\title{
Efeitos da suplementação de colina sobre o desempenho de poedeiras comerciais
}

[The effects of choline supplementation on the performance of laying hens]

R.J.C. Vasconcelos ${ }^{1}$, N.C. Baião ${ }^{2}$, L.J.C. Lara $^{2}$, R. Ecco ${ }^{2}$, A.L.C. Machado ${ }^{1}$, M.A. Pompeu ${ }^{1}$, J.S.R. Rocha ${ }^{1}$, D.J.A. Miranda ${ }^{1}$

\begin{abstract}
${ }^{1}$ Aluna de pós-graduação - Escola de Veterinária - Universidade Federal de Minas Gerais - Belo Horizonte, MG ${ }^{2}$ Escola de Veterinária - Universidade Federal de Minas Gerais - Belo Horizonte, MG
\end{abstract}

\section{RESUMO}

Os efeitos da suplementação de colina em dietas para poedeiras (Dekalb White) foram avaliados nas fases de cria/recria e de postura. O delineamento foi em esquema fatorial $2 \times 5$ (duas suplementações de colina de uma a 16 semanas de idade x cinco níveis de colina suplementada de 18 a 44 semanas de idade). Os níveis de colina utilizados foram $0,200,400,600$ e $800 \mathrm{mg} / \mathrm{kg}$ para cada grupo. A suplementação de colina em frangas com uma a 16 semanas de idade não afeta o desempenho nem as características macroscópicas e histopatológicas dos fígados durante essa fase. Os efeitos dos níveis de suplementação de colina sobre o desempenho das galinhas na fase de postura dependem da suplementação ou não dessa vitamina nas fases de cria/recria; ou seja, as aves que recebem suplemento de colina nessas fases apresentam maior exigência no período de postura.

Palavras-chave: colina, fígado, recria, poedeira, postura

\begin{abstract}
The effects of choline supplementation in diets for laying hens (Dekalb White) were evaluated from 1 to 44 weeks-old. The experimental design was a $2 x 5$ factorial arrangement (two choline supplementations from one to 16 weeks of age - with and without choline supplementation vs. five levels of choline supplementation from 18 to 44 weeks old. The choline level used in the diet for each group was 0, 200, 400, 600 and 800mg/kg). Choline supplementation used in birds with 1 to 16 weeks of age does not affect the performance of pullets and no gross and histological changes were observed in the liver during this phase. The effects of the choline supplementation levels in the laying phase on the hens' performance depend on the supplementation with this vitamin from 1 to 16 weeks old. The results of the experiment showed that birds reared for laying need a higher level of choline supplementation from 1 to 16 weeks old or birds reared for laying receiving higher levels of choline supplementation during 1 to 16 weeks old will need a higher level of choline supplementation in the laying phase.
\end{abstract}

Keywords: choline, liver, hen, rearing phase, laying phase

\section{INTRODUÇÃO}

Os níveis de vitaminas exigidos nas dietas para as aves domésticas têm aumentado ao longo dos anos devido ao melhoramento genético (Harms et al., 1990). As linhagens de poedeiras apresentam maturidade sexual precoce e maiores taxas de postura, porém o consumo de ração destas aves é cada vez menor. Essas características dificultam a suplementação vitamínica adequada em uma fórmula balanceada.
As recomendações sobre níveis de suplementação de colina para poedeiras variam muito entre os manuais das linhagens, as tabelas das instituições de pesquisa e as indicações dos fabricantes de suplementos vitamínicos e minerais.

A exigência de colina para galinhas em postura pode ser influenciada pelo nível desta na dieta durante a recria, ou seja, quando as frangas são alimentadas com rações sem adição de colina. Após oito semanas de idade, essas aves são

Recebido em 1 de março de 2012

Aceito em 6 de março de 2013

E-mail: rjcvasconcelos@hotmail.com 
capazes de sintetizar toda a colina exigida para ótima produção de ovos. Entretanto, quando as aves consomem ração de crescimento com adição de colina, faz-se necessária a suplementação da ração de postura para maximizar a produção de ovos (Nesheim et al., 1971; Tsiagbe et al.,1982; Leeson e Summers, 2001).

Objetivou-se avaliar os efeitos dos níveis de suplementação de colina nas dietas de poedeiras nas fases de cria/recria e de postura sobre o desempenho das aves, características dos ovos e características macroscópicas e histopatológicas dos fígados.

\section{MATERIAL E MÉTODOS}

No período de um dia a 16 semanas de idade, foram utilizadas 2.240 aves Dekalb White, as quais foram alojadas em um galpão convencional dividido em 28 boxes com 80 aves cada.

Durante as fases de cria/recria, as aves receberam as mesmas rações, exceto a suplementação de colina, na forma de cloreto de colina $60 \%$, sendo que metade das aves recebeu dieta suplementada e a outra metade recebeu dieta sem suplementação de colina. As composições das rações utilizadas nas fases de cria, recria I e II, com seus respectivos níveis nutricionais e períodos de utilização, estão apresentadas na Tab. 1. Foram avaliados o consumo de ração, o ganho de peso, a conversão alimentar e as características macroscópicas e histopatológicas dos fígados. O delineamento experimental foi o inteiramente ao acaso, com dois tratamentos (com e sem suplementação de colina). Para as avaliações de desempenho, foram utilizadas 14 repetições por tratamento, sendo o boxe com 80 aves considerado a repetição, e as médias foram comparadas pelo teste de Fisher. Para a avaliação das características dos fígados, às 15 semanas de idade, oito aves foram abatidas por tratamento, sendo cada fígado considerado uma repetição. Os tratamentos foram comparados pelo teste de Mann-Whitney, segundo Sampaio (2002). Os fígados de todas as aves abatidas foram avaliados macroscopicamente, considerando-se a coloração, a consistência e o tamanho. Os resultados das avaliações foram dados em escores de coloração do fígado: normal $=1$; levemente amarelado $=2 ;$ moderadamente amarelado $=3$; intensamente amarelado $=4 ; \mathrm{e}$ em escores de degeneração gordurosa: normal = 1 ; difusa leve $=2$; difusa moderada $=3$; difusa acentuada $=4$

Para cada ave, foram coletadas duas secções do lobo direito, fixadas em formol $10 \%$ e processadas rotineiramente para histopatologia. Os fígados embebidos na parafina foram recortados a cinco micrômetros de espessura, corados pela hematoxilina e eosina e avaliados no microscópio de luz comum.

Ao final da $16^{\mathrm{a}}$ semana de idade, as frangas foram transferidas para as gaiolas de postura $(45 \mathrm{~cm} \times 50 \mathrm{~cm})$ com densidade de $450 \mathrm{~cm}^{2} /$ ave. Para compor os tratamentos da fase de postura, foram utilizadas 900 aves alimentadas com dieta suplementada com colina e 900 aves alimentadas com dieta sem suplementação de colina durante as fases de cria/recria.

Na fase de postura, compreendida entre 18 e 44 semanas de idade, foram analisados os efeitos da suplementação ou não de colina nas fases de cria/recria e dos níveis de suplementação de colina na fase de postura sobre o desempenho das aves. O manejo foi semelhante ao utilizado na produção comercial, sendo o programa de luz de 16 horas de luz/dia (natural e artificial).

A composição da ração de postura e seus respectivos níveis nutricionais encontram-se na Tab. 1. As rações foram isonutritivas, exceto para o nível de colina. Os níveis nutricionais dos alimentos utilizados na formulação das rações seguiram os valores das tabelas brasileiras sobre exigências de aves e suínos (Rostagno et al., 2005). Desta forma, as 900 aves criadas sem suplementação de colina foram divididas em cinco tratamentos (A, B, C, D e E), sendo os níveis de suplementação durante a postura de zero, 200, 400, 600 e $800 \mathrm{mg} / \mathrm{kg}$, respectivamente. O mesmo foi feito com as 900 aves criadas com suplementação de colina durante as fases de cria/recria, as quais foram divididas em cinco tratamentos $(\mathrm{F}, \mathrm{G}, \mathrm{H}, \mathrm{I}$ e J), com os mesmos níveis de suplementação de colina citados anteriormente. $\mathrm{O}$ inerte das rações foi substituído pelas diferentes quantidades de cloreto de colina $60 \%$ adicionadas, de acordo com os tratamentos. Para as avaliações do desempenho na fase de postura, as metodologias utilizadas foram semelhantes às descritas por Oliveira et al. (2010). 
Tabela 1. Composição percentual das rações e seus valores nutricionais calculados

\begin{tabular}{|c|c|c|c|c|}
\hline \multirow{2}{*}{ Ingredientes } & \multicolumn{4}{|c|}{ Fase de criação } \\
\hline & Inicial $^{\mathrm{A}}$ & Recria I $^{\mathrm{B}}$ & Recria II $^{\mathrm{C}}$ & Produção $^{D}$ \\
\hline Milho grão & 64,000 & 61,000 & 67,000 & 65,200 \\
\hline Farelo de soja $45 \%$ & 28,400 & 22,000 & 16,500 & 21,000 \\
\hline Trigo farelo & 0,000 & 10,000 & 9,810 & 0,000 \\
\hline Calcário & 0,445 & 0,840 & 0,500 & 8,000 \\
\hline Farinha de carne $40 \% \mathrm{~PB}$ & 6,400 & 5,400 & 5,500 & 5,000 \\
\hline DL-Metionina & 0,130 & 0,120 & 0,130 & 0,125 \\
\hline $\mathrm{Sal}(\mathrm{NaCl})$ & 0,300 & 0,300 & 0,300 & 0,350 \\
\hline Supl. vitamínico ${ }^{1}$ & 0,100 & 0,100 & 0,100 & 0,100 \\
\hline Supl. mineral $^{2}$ & 0,050 & 0,050 & 0,050 & 0,050 \\
\hline L-Lisina $\mathrm{HCl}$ & 0,060 & 0,090 & 0,070 & 0,060 \\
\hline Salinomicina $12 \%$ & 0,035 & 0,035 & - & - \\
\hline Nicarbazina $25 \%$ & 0,020 & 0,020 & - & - \\
\hline Inerte & 0,050 & 0,045 & 0,040 & 0,115 \\
\hline Total $(\%)$ & 100,00 & 100,00 & 100,00 & 100,00 \\
\hline \multicolumn{5}{|l|}{ Níveis nutricionais } \\
\hline Colina $(\mathrm{mg} / \mathrm{kg})$ & 1.477 & 1.342 & 1.103 & 863 \\
\hline EMAn (kcal/kg) & 2.967 & 2.880 & 2.740 & 2.740 \\
\hline Proteína bruta (\%) & 21,0 & 19,0 & 17,0 & 17,0 \\
\hline Cálcio $(\%)$ & 1,03 & 1,055 & 1,051 & 1,051 \\
\hline Fósforo disponível (\%) & 0,45 & 0,42 & 0,45 & 0,45 \\
\hline Lisina digestível (\%) & 1,02 & 0,90 & 0,75 & 0,75 \\
\hline Metionina digestível (\%) & 0,42 & 0,38 & 0,39 & 0,39 \\
\hline Metionina + cistina dig. (\%) & 0,70 & 0,64 & 0,61 & 0,61 \\
\hline Sódio $(\%)$ & 0,18 & 0,17 & 0,18 & 0,18 \\
\hline
\end{tabular}

${ }^{\mathrm{A}}$ Ração fornecida de um dia a seis semanas de idade. Dois tratamentos: sem suplementação de colina e 500mg de cloreto de colina $(60 \%) / \mathrm{kg}$ de ração.

${ }^{\mathrm{B}}$ Ração fornecida de sete a 12 semanas de idade. Dois tratamentos: sem suplementação de colina e 450mg de cloreto de colina $(60 \%) / \mathrm{kg}$ de ração.

${ }^{\mathrm{C}}$ Ração fornecida de 13 a 17 semanas de idade. Dois tratamentos: sem suplementação de colina e 400mg de cloreto de colina $(60 \%) / \mathrm{kg}$ de ração.

${ }^{\mathrm{D}}$ Ração fornecida de 18 a 44 semanas de idade. Níveis de suplementação de colina: tratamentos $\mathrm{A} / \mathrm{F}=$ sem suplementação de colina, $\mathrm{B} / \mathrm{G}=200 \mathrm{mg}$ de cloreto de colina $(60 \%) / \mathrm{kg}$ de ração, $\mathrm{C} / \mathrm{H}=400 \mathrm{mg}$ cloreto de colina $(60 \%) / \mathrm{kg}$ de ração, $\mathrm{D} / \mathrm{I}=600 \mathrm{mg}$ cloreto de colina $60 \% / \mathrm{kg}$ de ração, E/J $=800 \mathrm{mg}$ cloreto de colina $(60 \%) / \mathrm{kg}$ de ração.

${ }^{1}$ Suplemento vitamínico (composição por kg do produto): vit. A 10.000.000UI, vit. D3 2.500.000UI, vit E 15.000UI, vit. K3 2.000mg, vit. B1 2.000mg, vit. B2 4.000mg, vit. B6 4.000mg, vit. B12 $15.000 \mathrm{mg}$, vit. C 50.000mg, niacina $30.000 \mathrm{mg}$, ácido fólico 500mg, ácido pantotênico $16.000 \mathrm{mg}$, biotina 60mg e BHT $125 \mathrm{mg}$.

${ }^{2}$ Suplemento mineral (composição por kg do produto): manganês $200.000 \mathrm{mg}$, zinco $125.000 \mathrm{mg}$, ferro $50.000 \mathrm{mg}$, cobre $15.000 \mathrm{mg}$, iodo $1.880 \mathrm{mg}$, selênio $400 \mathrm{mg}$.

O delineamento experimental para a fase de postura foi o inteiramente ao acaso, dividido em esquema fatorial $2 \times 5$ (dois níveis de suplementação de colina nas fases cria/recria $x$ cinco níveis de suplementação de colina na fase de postura). Para as avaliações do desempenho, foram utilizadas seis repetições de 30 aves cada, sendo cinco gaiolas, com seis aves cada, consideradas uma repetição. O peso médio dos ovos foi avaliado no período de 22 a 38 semanas de idade. Foi realizada análise de variância, e as médias dos níveis de suplementação de colina nas fases cria/recria foram comparados pelo teste de Fisher. As médias, de acordo com os níveis de colina na fase de postura, foram ajustadas ao modelo de regressão linear. A conversão alimentar e o número de ovos por ave alojada violaram os princípios da normalidade e da homocedasticidade, sendo avaliados pelo teste de Kruskal-Wallis (Sampaio, 2002).

O presente trabalho obteve aprovação do comitê de bioética e/ou de biossegurança para sua execução, segundo o protocolo 198/08. 


\section{RESULTADOS E DISCUSSÃO}

Não foram observadas diferenças $(\mathrm{P} \geq 0,05)$ no desempenho das frangas em relação aos níveis de suplementação de colina (Tab. 2). Os resultados de peso corporal estão de acordo com Nesheim et al. (1971) e Tsiagbe et al. (1982), os quais não observaram efeitos de dietas com e sem suplementação de colina para as aves Leghorn brancas. $\mathrm{O}$ mesmo foi descrito por Tsiagbe et al. (1982), que não notaram efeito significativo da suplementação de colina no consumo de ração e na conversão alimentar. Esses resultados indicam que, em dietas à base de milho, farelo de soja e farinha de carne e ossos para as aves de postura nas fases de cria/recria, não há necessidade de suplementação de colina. Provavelmente o conteúdo dessa vitamina nos referidos alimentos seja suficiente para atender a necessidade das aves nesse período. Além disso, as aves têm capacidade para sintetizar colina (Lesson e Summers, 2001).

Tabela 2. Efeitos dos níveis de suplementação de colina na dieta das aves de uma a 14 semanas de idade sobre o peso corporal (PC), o consumo de ração (CR), a conversão alimentar (CA) e as características macro e histopatológicas dos fígados às 15 semanas de idade

\begin{tabular}{cccccc}
\hline Colina $(\mathrm{mg} / \mathrm{kg})$ & $\mathrm{PC}(\mathrm{g})^{*}$ & $\mathrm{CR}(\mathrm{g})^{*}$ & $\mathrm{CA}(\mathrm{g} / \mathrm{g})^{*}$ & Macro** & Histo** \\
\hline SEM & 993 & 4341 & 4,553 & 2,5 & 2,5 \\
$\mathrm{COM}$ & 994 & 4401 & 4,611 & 2,0 & 2 \\
\hline CV $(\%)$ & 2,06 & 4,38 & 4,42 & - & - \\
\hline
\end{tabular}

*Médias não seguidas de letras são semelhantes estatisticamente pelo teste $\mathrm{F}(\mathrm{P} \geq 0,05)$.

**Medianas não seguidas de letras na coluna são estatisticamente semelhantes pelo teste de Mann-Whithney $(\mathrm{P} \geq 0,05)$.

Macro: macroscópicas $=$ escores de coloração do fígado: normal $=1$; levemente amarelado $=2$; moderadamente amarelado $=3$; intensamente amarelado $=4$.

Histo: histopatológicas $=$ escores de degeneração gordurosa: normal $=1$; difusa leve $=2$; difusa moderada $=3$; difusa acentuada $=4$

Não foram encontradas diferenças $(\mathrm{P} \geq 0,05)$ nas características macro e hsitopatógicas dos fígados em função dos tratamentos, o que está de acordo com Nesheim et al. (1971). Provavelmente, similar à relação feita acima com o peso e o desempenho das aves, a colina existente nos alimentos e a capacidade da ave em sintetizá-la possibilitaram níveis suficientes do componente para a síntese do LDL e assim conseguiram evitar o desenvolvimento da lipidose hepática significante.

Para porcentagem de postura (Tab. 3), houve interação entre suplementação de colina nas fases de cria/recria e os níveis de suplementação na fase de produção. Os níveis de suplementação influenciaram a porcentagem de postura, que apresentou efeito linear positivo quando as aves receberam colina na fase inicial, de acordo com a equação: $\mathrm{Y}=82,7064+0,00220450 \mathrm{X}$ $\left(\mathrm{R}^{2}\right.$ ajustado $\left.=97,7 \% ; \mathrm{P} \leq 0,01\right)$. Entretanto, quando as aves não receberam colina nas fases de cria/recria, os níveis de suplementação na postura exerceram efeito linear negativo, conforme a equação: $\mathrm{Y}=83,3032-0,00138726$ $\mathrm{X} \quad\left(\mathrm{R}^{2}\right.$ ajustado $\left.=89,7 \% ; \quad \mathrm{P} \leq 0,01\right)$. Estes resultados estão de acordo com Nesheim et al. (1971), Tsiagbe et al. (1982) e Leeson e Summers (2001), os quais relataram que, quando aves em crescimento consomem ração suplementada com colina, estas precisam receber dietas com essa vitamina na fase de produção. Desta forma, quando as aves recebem rações com suplementação de colina nas fases de cria/recria, maiores níveis devem ser adicionados às rações durante a fase de postura.

A maior produção de ovos foi alcançada pelas galinhas que receberam a ração suplementada com $800 \mathrm{mg} / \mathrm{kg}$ de colina. Entretanto, por se tratar de equação linear, não foi possível estabelecer um nível ótimo de suplementação dessa vitamina. Em contrapartida, nas aves que consumiram ração sem suplementação de colina nas fases inicial e de recria, a produção de ovos foi inversamente proporcional aos níveis de inclusão de colina nas rações utilizadas na fase de postura. 
Tabela 3. Efeito dos níveis de suplementação de colina nas rações sobre a porcentagem de postura (\%) e o consumo diário de ração $(\mathrm{g})$, no período de 18 a 44 semanas de idade

\begin{tabular}{|c|c|c|c|c|c|}
\hline \multirow{3}{*}{$\begin{array}{c}\text { Colina }(\mathrm{mg} / \mathrm{kg}) \\
\text { - postura }\end{array}$} & \multicolumn{5}{|c|}{ Colina $(\mathrm{mg} / \mathrm{kg})-$ cria/recria } \\
\hline & \multicolumn{2}{|c|}{ Porcentagem de postura (\%) } & \multicolumn{3}{|c|}{ Consumo diário de ração $(\mathrm{g})$} \\
\hline & SEM & $\mathrm{COM}$ & SEM & $\mathrm{COM}$ & Média \\
\hline Zero & 83,2 & 82,6 & 101,6 & 99,5 & 100,5 \\
\hline 200 & 83,2 & 83,2 & 102,5 & 100,6 & 101,5 \\
\hline 400 & 82,8 & 83,6 & 102,6 & 101,6 & 102,1 \\
\hline 600 & 82,3 & 83,9 & 102,8 & 102,9 & 102,9 \\
\hline 800 & 82,2 & 84,5 & 103,3 & 103,4 & 103,3 \\
\hline Média & & & $102,6 \mathrm{a}$ & $101,6 \mathrm{~b}$ & \\
\hline Regressão & $\mathrm{L}$ & $\mathrm{L}$ & & $\mathrm{L}$ & \\
\hline $\mathrm{CV}(\%)$ & & & & 1,78 & \\
\hline
\end{tabular}

$\mathrm{L}$ - Efeito linear do nível de suplementação de colina pelo teste $\mathrm{F}(\mathrm{P} \leq 0,05)$.

Letras distintas são estatisticamente diferentes pelo teste $\mathrm{F}(\mathrm{P} \leq 0,05)$.

Não houve interação entre os níveis de suplementação de colina nas fases de cria/recria e a fase de produção sobre o consumo diário de ração. Dessa forma, os modelos de regressão foram testados sobre a média dos resultados de suplementação de colina na ração de postura, conforme apresentado na Tab. 3.

Independente da suplementação de colina nas rações de cria/recria, os níveis de suplementação na fase de postura influenciaram o consumo diário de ração, que apresentou efeito linear positivo de acordo com a equação: $\mathrm{Y}=100,687$ $+0,0035069 X\left(R^{2}\right.$ ajustado $\left.=98,1 \% ; P \leq 0,05\right)$, o que demonstra que o aumento da inclusão de colina na ração de postura aumentou o consumo de ração. Independentemente da suplementação de colina na ração de postura, aves que receberam colina nas fases de cria/recria apresentaram menor consumo diário de ração de 18 a 44 semanas do que aves que não receberam colina. O maior consumo de ração foi alcançado com $800 \mathrm{mg} / \mathrm{kg}$ de suplementação. Apesar de significativa, a diferença é pequena (1g/ave), e esse efeito pode ter sido em razão do baixo coeficiente de variação (1,78\%). Este resultado está de acordo com os relatos de Ketola e Nesheim (1974) e Tsiagbe et al. (1982), os quais comprovaram haver aumento de consumo quando aumentada a suplementação de colina na dieta. Entretanto, por se tratar de equação linear, não foi possível a estimativa do nível ótimo de suplementação de colina na postura para essa variável.

A suplementação de colina nas rações de cria/recria e os níveis de colina utilizados nas rações na fase de postura não influenciaram $(\mathrm{p}>0,05)$ a conversão alimentar e o número de ovos por ave alojada (Tab. 4). Estes resultados estão de acordo com os de Tsiagbe et al. (1982) e Ruiz et al. (1983), que não observaram melhora na conversão alimentar, em razão da suplementação das dietas com colina.

Não houve interação entre os tratamentos sobre a viabilidade e o peso corporal, portanto os modelos de regressão foram testados sobre a média dos resultados de suplementação de colina (Tab. 5).

Tabela 4. Efeitos dos níveis de suplementação de colina nas rações sobre a conversão alimentar e o número de ovos por ave alojada, no período de 18 a 44 semanas de idade

\begin{tabular}{cccccc}
\hline \multirow{2}{*}{ Colina $(\mathrm{mg} / \mathrm{kg})$ - postura } & \multicolumn{3}{c}{ Colina $(\mathrm{mg} / \mathrm{kg})$} & cria/recria \\
\cline { 2 - 3 } \cline { 5 - 6 } \cline { 5 - 6 } & \multicolumn{2}{c}{ Conversão alimentar $(\mathrm{g} / \mathrm{g})$} & COM & & Ovos por ave alojada \\
\cline { 2 - 3 } & 1,900 & 1,877 & & 150 & COM \\
\hline Zero & 1,953 & 1,877 & & 147 & 148 \\
400 & 1,904 & 1,894 & & 152 & 151 \\
600 & 1,877 & 1,922 & & 152 & 150 \\
800 & 1,958 & 1,883 & & 149 & 153 \\
\hline
\end{tabular}

Medianas não seguidas de letras são estatisticamente semelhantes pelo teste de Kruskal-Wallis ( $\mathrm{P}>0,05)$. 
Tabela 5. Efeito dos níveis de suplementação de colina nas rações de cria/recria e postura sobre a viabilidade das aves (\%), no período de 18 a 44 semanas de idade, e sobre o peso das aves (g) às 44 semanas de idade

\begin{tabular}{|c|c|c|c|c|c|c|}
\hline \multirow{3}{*}{ Colina $(\mathrm{mg} / \mathrm{kg})$ - postura } & \multicolumn{6}{|c|}{ Colina (mg/kg) - cria/recria } \\
\hline & \multicolumn{3}{|c|}{ Viabilidade (\%) } & \multicolumn{3}{|c|}{ Peso das aves $(\mathrm{g})$} \\
\hline & SEM & COM & Média & SEM & COM & Média \\
\hline Zero & 99,68 & 99,36 & 99,52 & 1.555 & 1.484 & 1.520 \\
\hline 200 & 99,62 & 99,31 & 99,46 & 1.548 & 1.535 & 1.542 \\
\hline 400 & 99,56 & 99,25 & 99,40 & 1.535 & 1.533 & 1.534 \\
\hline 600 & 99,50 & 99,17 & 99,34 & 1.596 & 1.592 & 1.594 \\
\hline 800 & 99,43 & 99,11 & 99,27 & 1.581 & 1.566 & 1.574 \\
\hline Média & $99,6 \mathrm{a}$ & $99,2 \mathrm{~b}$ & $\mathrm{~L}$ & 1.562 & 1.542 & $\mathrm{~L}$ \\
\hline $\mathrm{CV}(\%)$ & & 0,12 & & & 3,10 & \\
\hline
\end{tabular}

$\mathrm{L}$ - Efeito linear do nível de suplementação de colina na postura pelo teste $\mathrm{F}(\mathrm{p} \leq 0,05)$.

Letras distintas são estatisticamente diferentes pelo teste $\mathrm{F}(\mathrm{P} \leq 0,05)$.

Valores não seguidos de letras na linha são semelhantes pelo teste $\mathrm{F}(\mathrm{P}>0,05)$.

Independentemente da suplementação de colina nas rações de cria/recria, os níveis de suplementação de colina nas rações de postura influenciaram a viabilidade, que apresentou efeito linear negativo, de acordo com a equação: $\mathrm{Y}=99,5231-0,00030914 \mathrm{X}\left(\mathrm{R}^{2}\right.$ ajustado $=$ $99,7 \% ; \mathrm{P} \leq 0,05)$. Isso indica que o aumento da inclusão de colina na ração de postura diminui a viabilidade das aves. Independentemente da suplementação de colina na postura, aves que receberam suplementação de colina nas fases de cria/recria apresentaram menor viabilidade do que aves que não receberam a suplementação. Entretanto, a diferença, apesar de significativa, é pequena $(0,04 \%)$, portanto o efeito significativo pode ter sido em razão do baixo coeficiente de variação $(0,12 \%)$ dessa resposta. Estes resultados estão em desacordo com os relatados por Tsiagbe et al. (1982), que não observaram aumento na mortalidade com o aumento do nível de suplementação de colina.

As aves que receberam suplementação de colina nas fases de cria/recria apresentaram peso médio semelhante ao das aves que não receberam suplementação nessas fases, não sendo levada em consideração a suplementação de colina na ração de postura. Independentemente da suplementação de colina nas fases iniciais, os níveis de suplementação na postura influenciaram o peso das aves, que apresentou efeito linear positivo: $\mathrm{Y}=1520,43+$ $0,08200 \mathrm{X}\left(\mathrm{R}^{2}\right.$ ajustado $\left.=59,2 \% ; \mathrm{p} \leq 0,05\right)$. Isso indica que o aumento da inclusão de colina na ração de postura implica aumento no peso das aves. Estes resultados estão de acordo com Schexnailder e Griffith (1973) e Ketola e
Nesheim (1974), os quais não encontraram o efeito da suplementação de colina sobre o peso das aves. Porém, contradizem os de Tsiagbe $e t$ al. (1982), que não encontraram esse efeito.

$\mathrm{Na}$ Tab. 6, observa-se que não houve interação entre os tratamentos para o peso dos ovos. Os modelos de regressão, linear e quadrático, não se ajustaram às médias dessa resposta em razão da suplementação de colina nas rações de postura.

Tabela 6. Efeitos dos níveis de suplementação de colina sobre o peso médio dos ovos $(\mathrm{g})$, de 22 a 38 semanas de idade

\begin{tabular}{cccc}
\hline Colina $(\mathrm{mg} / \mathrm{kg})$ & \multicolumn{3}{c}{ Colina $(\mathrm{mg} / \mathrm{kg})$ - cria/recria } \\
\cline { 2 - 4 } - postura & SEM & COM & Média \\
\hline Zero & 58,45 & 58,92 & 58,69 \\
200 & 57,52 & 59,59 & 58,56 \\
400 & 59,00 & 58,66 & 58,83 \\
600 & 57,63 & 59,50 & 58,55 \\
800 & 59,03 & 58,91 & 58,97 \\
\hline Média & $58,30 \mathrm{~b}$ & $59,10 \mathrm{a}$ & $\mathrm{ns}$ \\
\hline $\mathrm{CV}(\%)=0,19$ & & & \\
\hline
\end{tabular}

ns - Efeito não significativo pelo teste $\mathrm{F}(\mathrm{P}>0,05)$.

Letras distintas são estatisticamente diferentes pelo teste $\mathrm{F}(\mathrm{P} \leq 0,05)$.

Independentemente da suplementação de colina na ração de postura, aves que receberam suplementação de colina nas fases de cria/recria apresentaram maior peso dos ovos de 22 a 38 semanas de idade do que aquelas que não receberam a suplementação. Entretanto, a diferença, apesar de significativa, é pequena $(0,8 \%)$. O efeito significativo pode ter sido em razão do baixo coeficiente de variação $(0,19 \%)$. Este resultado corrobora os de Balloun (1956), Daghir et al. (1960), Ruiz et al. (1983) e Parsons 
e Leeper (1984), que não encontraram diferença no peso dos ovos quando as poedeiras foram alimentadas com rações suplementadas com colina. Entretanto, Tsiagbe et al. (1982) relataram que a suplementação de colina nas rações para poedeiras resulta no aumento do peso dos ovos.

\section{CONCLUSÃO}

Os resultados desse estudo mostraram que a suplementação com colina nas fases de cria/recria não afeta o desempenho das frangas. Paralelamente, a não suplementação não causa lipidose hepática significativa. Os efeitos dos níveis de suplementação de colina sobre o desempenho das galinhas na fase de postura dependem da suplementação ou não dessa vitamina nas fases de cria/recria; ou seja, as aves que recebem suplemento de colina nessas fases apresentam maior exigência no período de postura. Para recomendar a suplementação ótima de colina que resulte na melhor produção de ovos e de consumo de ração, valores de suplementação acima dos avaliados devem ser testados a fim de possibilitar o ajuste de um modelo de regressão que permita estimar a melhor resposta à suplementação.

\section{AGRADECIMENTOS}

Os autores agradecem à Fundação de Amparo à Pesquisa do Estado de Minas Gerais (FAPEMIG), por fornecer fundos para publicação da pesquisa.

\section{REFERÊNCIAS}

BALLOUN, S.L. Choline and tallow in breeder hen diets. Poult. Sci., v.35, p.737-738, 1956.

DAGHIR, N.J.; MARION, W.W.; BALLOUN, S.L. Influence of dietary fat and choline on serum and egg yolk cholesterol in the laying chicken. Poult. Sci., v.39, p.1459-1465, 1960.
HARMS, R.H.; RUIZ, N.; MILES, R.D. Research note: Conditions necessary for a response by the commercial laying hen to supplemental choline and sulfate. Poult. Sci., v.69, p.1226-1229, 1990.

KETOLA, H.G.; NESHEIM, M.C. Influence of dietary protein and methionine levels on the requirement for choline by chickens. J. Nutrit., v.104, p.1484-1489, 1974.

LEESON, S.; SUMMERS, J.D. Vitamins. In: LEESON, S. and SUMMERS, J.D. Comm. Poult. Nutrit. 4.ed. Guelph: University Books, 2001. p.176330 .

NESHEIM, M.C.; NORVELL, M.J.; CEBALLOS, E.; et al. The effect of choline supplementation of diets for growing pullets and laying hens. Poult. Sci., v.50, p.820-831, 1971.

OLIVEIRA, D.D.; BAIÃO, N.C.; CANÇADO, S.V.; et al. Fontes de lipídios na dieta de poedeiras: desempenho produtivo e qualidade de ovos. Arq. Bras. Med. Vet. Zootec., v.62, p.718-724, 2010.

PARSONS, C.M.; LEEPER, R.W. Choline and methionine supplementation of layer diets varying in protein content. Poult. Sci., v.63, p.1604-1609, 1984.

ROSTAGNO, H.S.; ALBINO, L.F.T.; DONZELE, J.L.; et al. Tabelas Brasileiras para Aves e Suínos Composição de alimentos e exigências nutricionais. Viçosa: UFV, 2005. 186p.

RUIZ, N.; MILES, R.D.; WILSON, H.R. et al. Choline supplementation in the diets of aged White Leghorn hens grouped according to body weight. Poult. Sci., v.62, p.1028-1032, 1983.

SAMPAIO, I.B.M. Estatística aplicada à experimentação animal. 2.ed. Belo Horizonte: FEPMVZ, 2002. 265p.

SCHEXNAILDER, R.; GRIFFITH, M. Liver fat and egg production of laying hens as influenced by choline and other nutrients. Poult. Sci., v.52, p.1188-1194, 1973.

TSIAGBE, V.K.; KANG, C.W.; SUNDE, M.L. The effect of choline supplementation in growing pullet and laying hen diets. Poult. Sci., v.61, p.2060-2064, 1982. 